\title{
MEASUREMENTS AT FP3 IN SUPPORT OF PECAN SCIENTIFIC Objectives Using MPL-111 Lidar
}

\author{
Kristen Pozsonyi ${ }^{1}$, Natalie Midzak ${ }^{2}$, Christina Prestine ${ }^{3}$, Richard Clark ${ }^{4}$ \\ ${ }^{I}$ Millersville University,nowat U. Alabama in Huntsville,USA, kristenpozsonyi@yahoo.com \\ ${ }^{2}$ Millersville University, now at U. North Dakota, USA \\ ${ }^{3}$ Millersville University, USA \\ ${ }^{4}$ Department of Meteorology, Millersville University, USA
}

\section{ABSTRACT}

This paper will report on the data collected by a Sigma Space Micropulse Lidar (MPL-111), and how these measurements, when integrated with other data, helps to inform our analysis of two cases of the Great Plains nocturnal Low-Level Jet (LLJ) in the vicinity of FP3.

\section{INTRODUCTION}

The primary objective of the Plains Elevated Convection at Night (PECAN) campaign was to gain a better understanding of conditions and mechanisms contributing to nocturnal precipitation. Most of the summertime rainfall over the Great Plains occurs at night, often well after the maximum in daytime heating and when the nocturnal boundary exhibits static stability.

The PECAN field campaign spanned the period from 1 June 2015 to 15 July 2015. The domain for this project included Kansas, northern Oklahoma, and Southern Nebraska, but eventually spread outward to other locations across the Great Plains. PECAN was a collaborative event between eight research facilities and 14 universities. There were a total of 31 Intensive Observing Periods (IOPs) conducted during PECAN.

PECAN focused on the study of nocturnal convection initiation, the internal structure of mesoscale systems, and propagating wave-like disturbances that are spawned as a result of these convective storms. The experimental design included six fixed and four mobile ground-based facilities comprising the PECAN Integrated Sounding Arrays (PISAs), along with many more facilities. FP3 was one of six fixed PISA sites and located at Ellis, Kansas as in Fig. 1.

PECAN had five main research objectives: 1) explain the characteristics and processes that lead to pristine nocturnal convective initiation (CI) and early phases of large-scale storm systems; 2) explore the evolution of bores and their impact on maintaining MCSs; 3) investigate the initiation, structure, and evolution of the LLJ and its relation to CI; 4) study the microphysical structure of MCSs; and 5) improve the prediction of nocturnal convection, which will be useful to operational forecasting and climate models (Geerts et al. 2017).

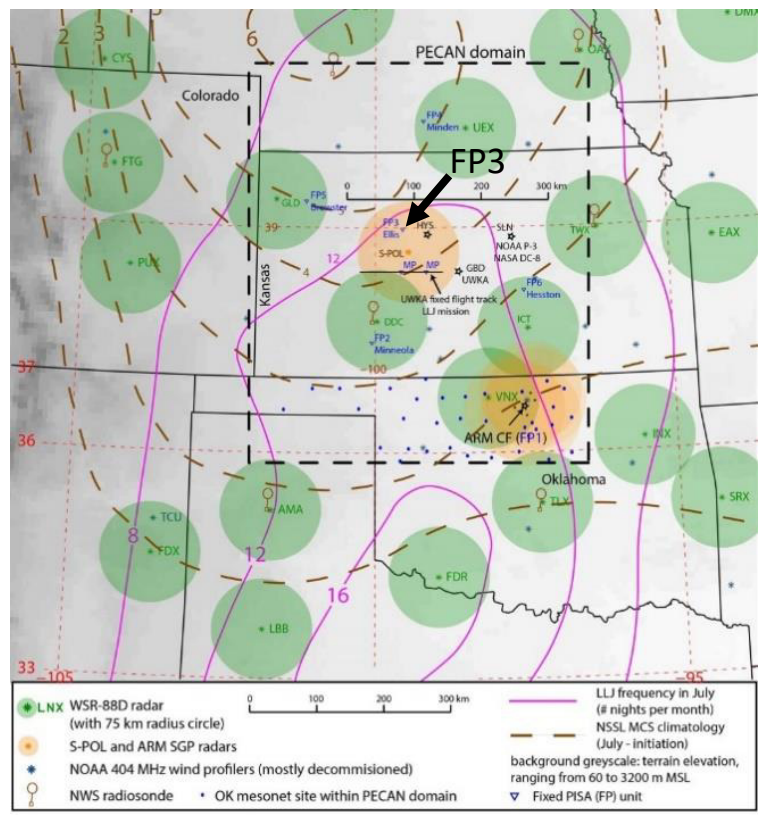

Figure 1: Map of PECAN domain and facilities

The primary instrument relevant to this paper, the Sigma Space Micropulse Lidar (MPL)-111, is part of the Millersville [University] 
Atmospheric Research and Aerostat Facility (MARAF), which is a multi-capability boundary layer facility that includes tethered and free balloon atmospheric profiling systems, $10 \mathrm{~m}$ flux tower, Medium Frequency Acoustic Sodar (MFAS) with a radio acoustic sounding system (RASS), and a full suite of trace gas analyzers.

The measurements obtained by MARAF are used to here to report on the structure and evolution of two very different LLJs: a $15 \mathrm{~m} \mathrm{~s}^{-1}$ LLJ on 10 June 2015 that resided about 200-300 $\mathrm{m}$ above ground level (AGL), and a $30 \mathrm{~m} \mathrm{~s}^{-1}$ LLJ residing near $500 \mathrm{~m}$ AGL with a boundary layer in dynamic instability due to shear. The LLJ is known to be a recurring feature of the summertime boundary layer over the central plains, and is responsible for the influx of heat and moisture important to the initiation and maintenance of convection across the PECAN domain.

The MPL-111 was used mainly as a turnkey instrument to determine the height of the atmospheric boundary layer (ABL) and aerosol layer (AL). The MPL-111 has the ability to generate three primary products that are compiled from 30-second averages: Raw, $\mathrm{R}^{2}$, and Normalized Relative Backscatter (NRB). The backscatter plot depicts the height of aerosols, cloud base (it serves as a ceilometer), and the height of the ABL up to five kilometers. Particular interest was given to the time-height series of the ABL and AL from the derived normalized relative backscatter. These products can be found on the PECAN field campaign website (http://catalog.eol.ucar.edu/pecan).

\subsection{Site Specifications}

There were multiple facilities taking part in this field campaign, including multiple mobile integrated sounding arrays and six fixed sites throughout the domain. Millersville University and NCAR brought facilities to FP3, with NCAR maintaining a $30 \mathrm{~m}$ instrumented tower, $915 \mathrm{MHz}$ profiler, and other instruments north of I-70, and Millersville with its MARAF facility just south of I-70 (see Fig. 2.)

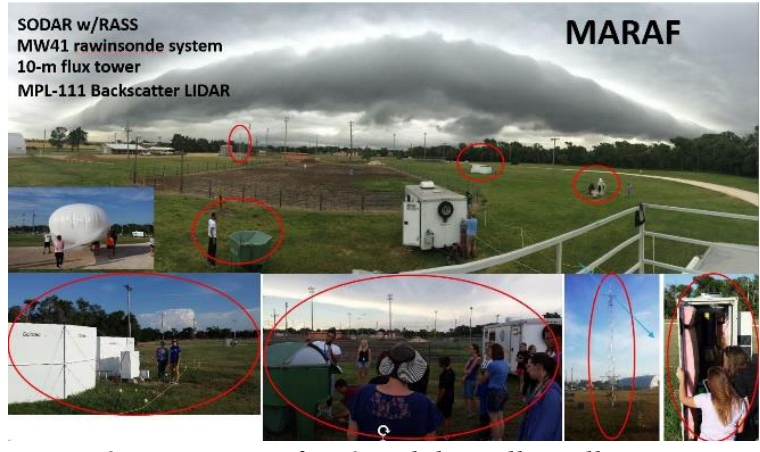

Figure 2: Panorama of FP3 and the Millersville Atmospheric Research and Aerostat Facility, which occupied the Ellis Fairground.

\section{METHODOLOGY}

Although FP3 accommodated an array of instrumentation, the focus for this study was on the Sigma Space MPL-111 Lidar. Measurements taken by this Lidar were gathered daily throughout the duration of this campaign. The instrument ran continuously, providing autonomous data collection using 30 meter bin resolution. The $\min / \max$ range for this MPL is $150 \mathrm{~m} / 25 \mathrm{~km}$, however, for this campaign we only recorded data up to $5 \mathrm{~km}$, focusing on the

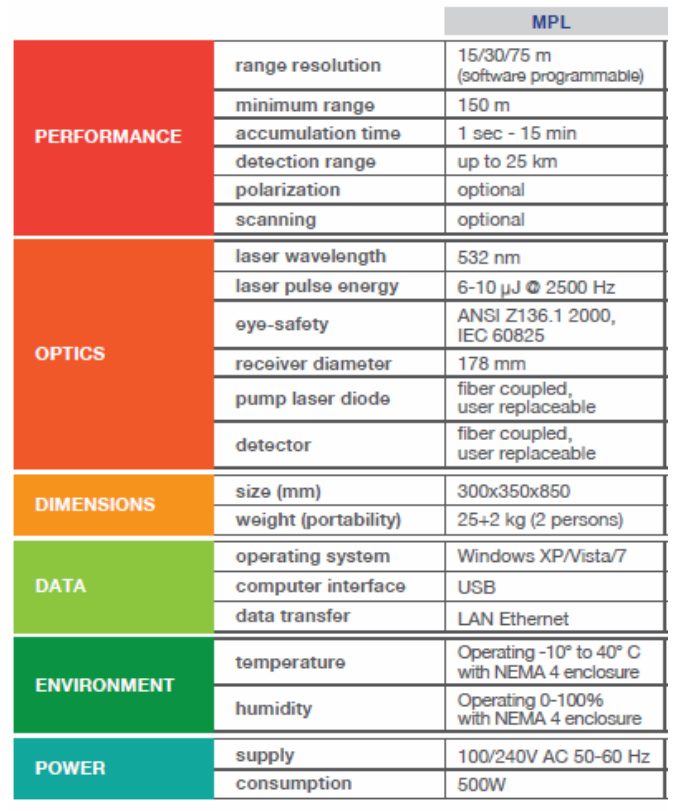

Figure 3: Specifications for the MPL-111

boundary layer conditions. Other specifications for this are given in Figure 3. 


\section{RESULTS}

Characteristics of the LLJ were observed with the MPL and are combined with data from the $10 \mathrm{~m}$ flux tower and the MFAS Sodar and upper air profiles from the RS41-SGP radiosonde to describe the vertical structure and evolution of the LLJ.

\subsection{Weak Jet - 10 June 2015}

One of the weaker LLJ cases that was observed during the campaign occurred on 10 June 2015 with a peak wind speed of $15 \mathrm{~m} \mathrm{~s}^{-1}$ around 0900 UTC. Wind profiles taken every three hours

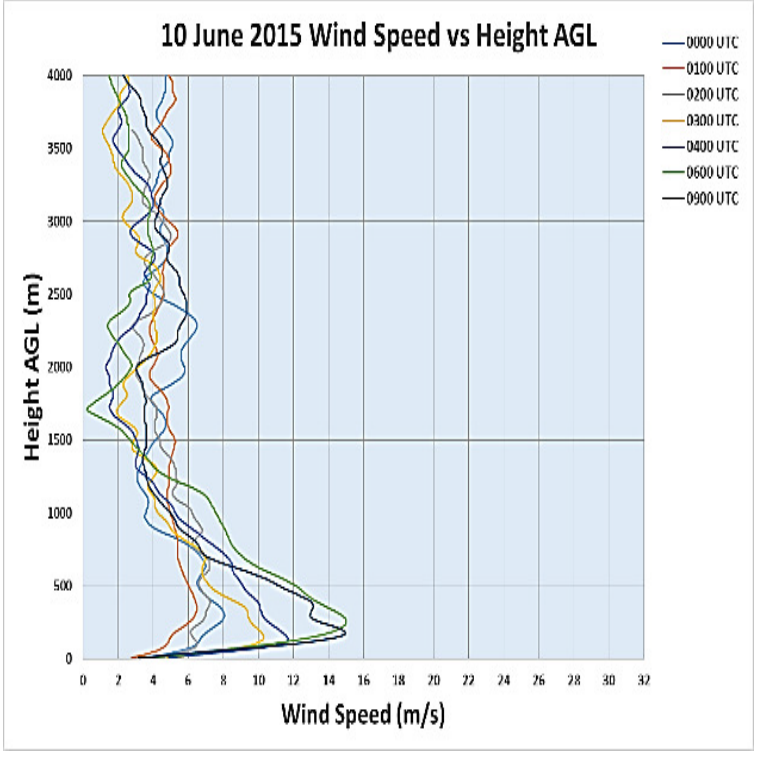

Figure 4: Wind profiles for 10 June 2015 from 0000 UTC to 0900 UTC are shown in Fig. 4. Around 0300 UTC there is an abrupt acceleration of the LLJ and this is correlated with an increase in shear and a commensurate increase in the Lidar backscatter from the level of maximum winds to $1-1.2 \mathrm{~km}$ (see dashed line in Fig. 6). The top of the boundary layer, which is represented by the solid line and correlated with the capping inversion seen in the virtual potential temperature profiles in Fig. 5 , exhibits little variability over the nighttime period. The relatively constant thickness of the two high-backscatter levels over the nighttime duration shown in Fig. 6 is consistent with a

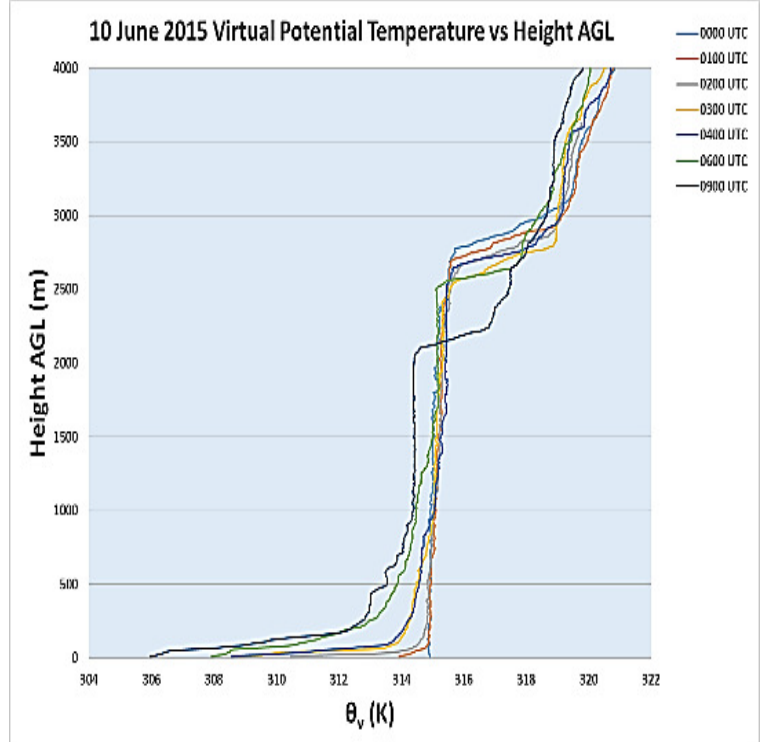

Figure 5: Virtual potential temperature profiles - 10 June 2015

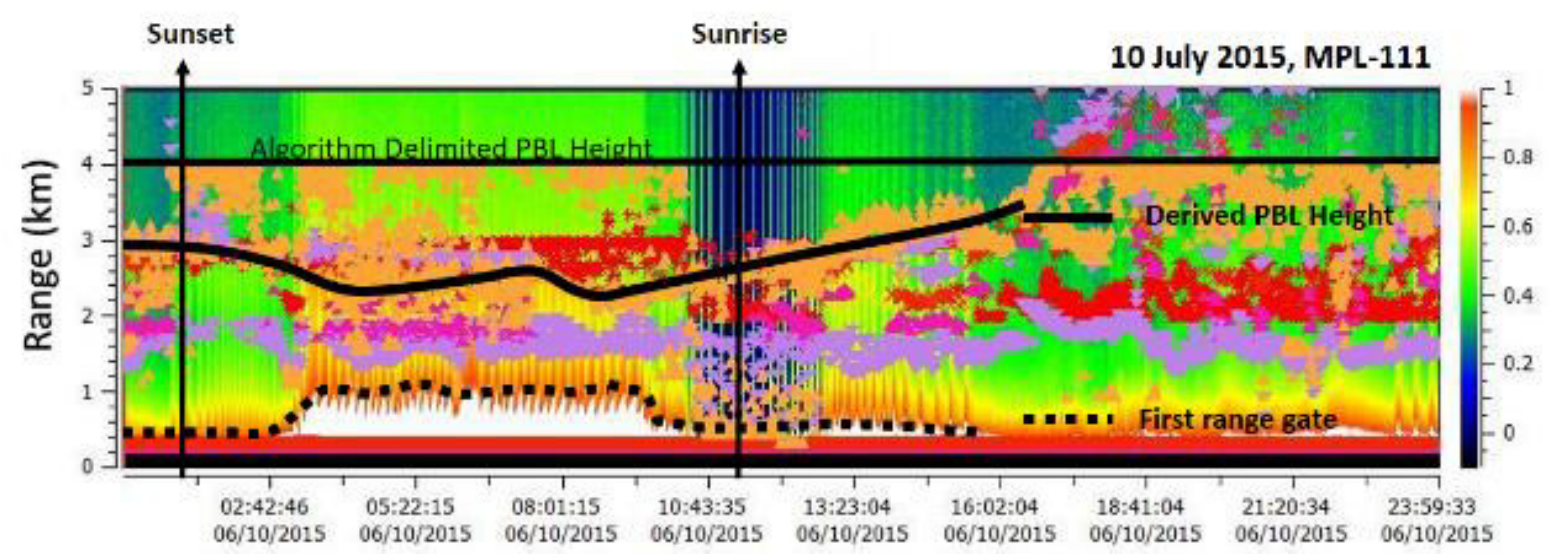

Time

Figure 6: NRB product-10 June 2015 LLJ. The vertical lines are an artifact of the air conditioning system in the enclosure. 
residual layer between 500 and 2500-3000 m that is largely unaffected by the dynamic changes and kinematic structure of this weaker LLJ.

\subsection{Strong Jet - 22 June 2015}

A stronger LLJ event occurred on 22 June 2015 reaching peak wind speed of $31 \mathrm{~m} \mathrm{~s}^{-1}$ around 1030 UTC. Wind profiles from soundings launched every 1.5 to 3 hours reveal a deep layer of maximum winds at an altitude around

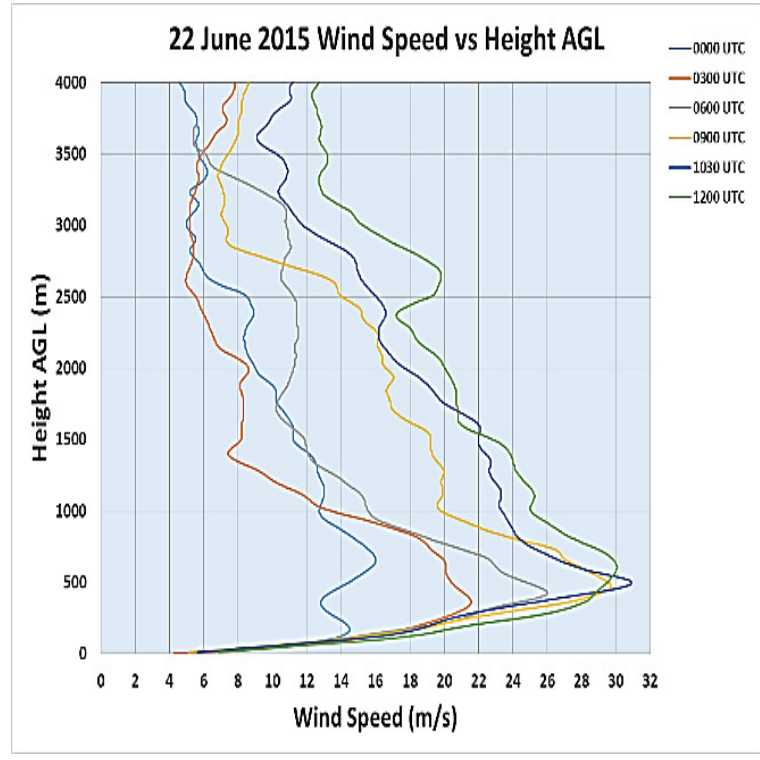

Figure 7: Wind profiles for 22 June 2015

$500 \mathrm{~m}$ (Fig. 7). Strong shear both above and below the LLJ core generates dynamic instability (Richardson numbers remain less than 0.25 for the entire duration). But there is a distinct transition from high shear to lesser shear and strong static stability to weaker stability (Fig. 8) in the layer $1-1.2 \mathrm{~km}$, giving rise to the Lidar backscatter shown in Fig. 9 (dashed line). Note that this layer remains deep and fairly constant over the event duration, with only a slight reduction in altitude with time as the LLJ weakens. The height of the top of the boundary layer, another concentrated layer of Lidar scatter and represented by the solid line, increases in altitude from $2-3.3 \mathrm{~km}$ from 0330

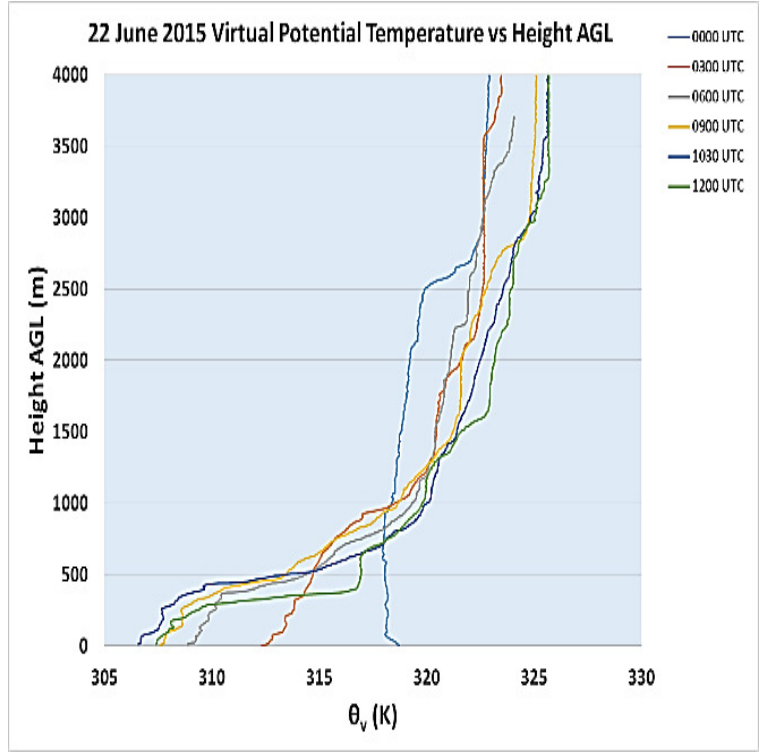

Figure 8: Virtual potential temperature profiles - 22 June 2015

UTC on as the LLJ accelerates, generates turbulence above the LLJ core and produces a

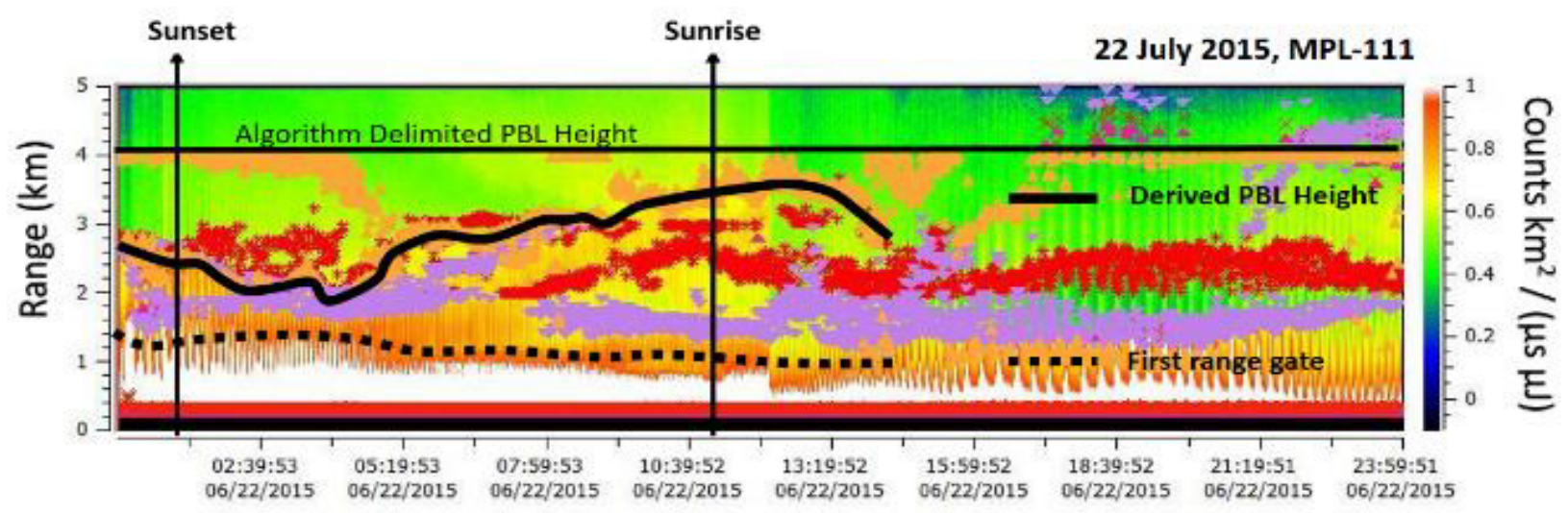

Figure 9: Same as Figure 6 except that this is a strong LLJ - 22 June 2015. 
thickening residual layer as the LLJ continues to accelerate.

\section{CONCLUSIONS}

Two very different LLJ case studies were analyzed using data from upper air profiles and the MPL-111 Lidar. The MPL is a useful tool for capturing the time-height evolution of the boundary layer and filling in gaps remaining from other observations. The weaker LLJ exhibits little change once the LLJ develops, even as static stability increases. We believe that the wind is not strong enough to create the instability and turbulent mixing above the layer of maximum winds to affect the height of the boundary layer. Conversely, the strong LLJ on 22 June generated strong shear, consequent instability and turbulent eddies that moved momentum and heat throughout the residual layer owing to the weak static stability, causing the depth of the boundary layer to increase in time.

These preliminary findings can help inform future investigations on the structure and evolution of the LLJ.

\section{REFERENCES}

Geerts, B., D. Parsons, C.L. Ziegler, T.M. Weckwerth, M.I. Biggerstaff, R.D. Clark, M.C. Coniglio, B.B. Demoz, R.A. Ferrare, W.A. Gallus, K. Haghi, J.M. Hanesiak, P.M. Klein, K.R. Knupp, K. Kosiba, G.M. McFarquhar, J.A. Moore, A.R. Nehrir, M.D. Parker, J.O. Pinto, R.M. Rauber, R.S. Schumacher, D.D. Turner, Q. Wang, X. Wang, Z. Wang, and J. Wurman, 2017: The 2015 Plains Elevated Convection at Night Field Project. Bull. Amer. Meteor. Soc., 98, 767-786, doi: 10.1175/BAMS-D-15-00257.1. 